\title{
Vitamin $D$ postpones the progression of epithelial ovarian cancer induced by 7, 12-dimethylbenz [a] anthracene both in vitro and in vivo
}

This article was published in the following Dove Press journal:

OncoTargets and Therapy

19 April 2016

Number of times this article has been viewed

\section{Lizhi Liu',* \\ Zhiyong $\mathrm{Hu}^{2, *}$ \\ Hemei Zhang ${ }^{3}$ \\ Yongfeng Hou' \\ Zengli Zhang ${ }^{4}$ \\ Guangming Zhou ${ }^{5}$ \\ Bingyan $\mathrm{Li}^{1,5}$ \\ 'School of Public Health, Medical College of Soochow University, Suzhou, ${ }^{2}$ Department of Chronic Disease Management, Lishui Center for Disease Control and Prevention, Lishui, ${ }^{3}$ Department of Chronic Disease Management, Wenzhou Center for Disease Control and Prevention, Wenzhou, ${ }^{4}$ Department of Labor Hygiene and Environmental Health, School of Public Health, Soochow University, Suzhou, ${ }^{5}$ School of Radiation Medicine and Protection, Soochow University, Suzhou, People's Republic of China}

*These authors contributed equally to this work

Correspondence: Bingyan Li Medical College of Soochow University, 199 Ren'ai Road, Suzhou Industrial Park, Suzhou 215I23, People's

Republic of China

$\mathrm{Tel}+8651265882636$

Fax +8651265880070

Email bingyanli@suda.edu.cn
Purpose: Ovarian cancer is the most lethal malignancy of the female reproductive system, and the prevention and treatment of ovarian carcinoma are still far from optimal. Epidemiological studies reported that ovarian cancer risk was inversely associated with low level of 25-hydroxy vitamin D [25(OH)]. Therefore, this study focuses on exploring the chemoprevention of vitamin D on epithelial ovarian cancer induced by 7, 12-dimethylbenz [a] anthracene (DMBA).

Methods: The mouse ovarian surface epithelial cells were isolated from estrus mice by mild trypsinization and maintained in completed culture medium by repeated passaging. The malignant transformation of mouse ovarian surface epithelial cells was induced by DMBA in vitro. DMBA was directly injected into the bursa of mouse ovary to produce optimized in vivo ovarian cancer model.

Results: The results indicate that $1 \alpha, 25$ dihydroxyvitamin D3 may delay malignant transformation of mouse ovarian surface epithelial cells induced by DMBA and significantly decreased the colony formation rate from $18.4 \%$ to $3.2 \%(P<0.05)$. There was a negative correlation between incidence of DMBA-induced tumor and 25-hydroxy vitamin D level $\left(R^{2}=0.978, P<0.05\right)$. Vitamin D3 can delay the progression of ovarian cancer induced by DMBA, and the administration of vitamin D3 during the whole process worked more effectively than the administration only during tumor initiation or promotion. Moreover, we found the vitamin D3 increased the expression of E-cadherin and vitamin D receptor while it decreased the expression of $\beta$-catenin.

Conclusion: We succeeded in establishment of epithelial ovarian cancer models both in vitro and in vivo. The DMBA-implanted model in mice yields high incidence and specificity of epithelial derived tumors. We also found that vitamin D delays the progression of ovarian cancer. However, spontaneous epithelial ovarian carcinoma models are still to be explored for testing the preventive effects of vitamin D on epithelial ovarian cancer.

Keywords: vitamin D, epithelial ovarian cancer, DMBA, experimental animal model, chemoprevention, vitamin $\mathrm{D}$ receptor

\section{Introduction}

GLIBOCAN 2012 reports that the estimated incidence of ovarian cancer is 6.1/100,000, and mortality is $3.8 / 100,000 .{ }^{1}$ Although it does not have the highest morbidity, ovarian cancer is the most lethal malignancy of the female reproductive system. A high mortality rate of ovarian cancer is ascribed to its aggressiveness and the fact that the majority of patients are diagnosed in the advanced stages of the disease. Moreover, there has been little change to the 5-year cumulative survival rate for epithelial ovarian carcinoma (EOC) since platinum-based treatment was universally introduced more than 30 years ago. ${ }^{2}$ As a result of chemosensitivity in the treatment of patients 
suffering from ovarian cancer in the last decade, there is a constant need for new precaution and treatment strategies. The benefit of such an approach is the possibility of enhancing the therapeutic effects of a drug, which is the basis of a standard therapy. A promising candidate for this strategy is vitamin $\mathrm{D}$.

The active form of vitamin $\mathrm{D}$ acts as a protective role in several cancers. ${ }^{3-6}$ Epidemiological and clinical data suggest that the low level of circulating 25-hydroxy vitamin D $[25(\mathrm{OH})]$, a widely accepted biomarker of vitamin D status, leads to an increased risk of ovarian cancer. ${ }^{7-11}$ Women with a serum $25(\mathrm{OH}) \mathrm{D}$ level of $>30 \mathrm{ng} / \mathrm{mL}^{12}$ had a significantly better survival rate than those with level of $20-29.9 \mathrm{ng} / \mathrm{mL}$. And there was a $7 \%$ reduction in risk of death per $4 \mathrm{ng} / \mathrm{mL}$ increment in serum $25(\mathrm{OH}) \mathrm{D}$. Research ${ }^{13}$ suggests that an active metabolite of vitamin $\mathrm{D}, 1 \alpha, 25$ dihydroxyvitamin $\mathrm{D} 3\left[1 \alpha, 25(\mathrm{OH})_{2} \mathrm{D}_{3}\right]$, also known as calcitriol, or vitamin D analogues might have potential as anticancer agents because their administration inhibits proliferation, activates apoptotic pathways, and inhibits angiogenesis, via binding to the vitamin D receptor (VDR).

Ovarian cancer continues to be a poorly understood disease with an extremely poor prognosis. Ninety percent of human ovarian malignancies are thought to derive from epithelial tissue, but the etiology of EOC is poorly understood. One reason for the slow progress made in understanding the biology of ovarian cancer and translating that knowledge into substantial clinical benefits has been a lack of clinically representative model systems that mimic the progression of the human disease. A good animal model is urgently needed for representing human ovarian cancer and understanding the pathogenesis of the disease in order to test new treatment strategies. Some efforts have been put into animal models ${ }^{14-16}$ designed for ovarian cancer for decades. These models have included whole-body irradiation, chemical induction, genetic manipulation, and xenograph development. A powerful organ-specific laboratory carcinogen, 7, 12-dimethylbenz [a] anthracene (DMBA), is always used to induce various kinds of cancer, such as breast, ovarian, lung, and skin. ${ }^{17}$ However, in the mouse model for ovarian cancer, there is only one DMBA-induced malignancy mouse model, and the model was used by menopause mice. ${ }^{15}$ Therefore, this study focuses on establishing both the mouse model of ovarian cancer and malignant transformation of mouse ovarian surface epithelial (MOSE) cells induced by DMBA. Meanwhile, vitamin $\mathrm{D}$ was administered into mice in different phases of ovarian cancer (initiation and propagation). The aim of our study was to test the chemoprevention of vitamin D on DMBA-induced ovarian cancer.

\section{Materials and methods}

\section{Reagent and mice}

Vitamin D3 and 1,25(OH) ${ }_{2} \mathrm{D}_{3}$ were purchased from Shanghai General Pharmaceutical Company (Shanghai, People's Republic of China) and Sigma-Aldrich Co. (St Louis, MO, USA), respectively. Dulbecco's Modified Eagle's Medium/Nutrient Mixture F-12 (DMEM/F12) medium and supplementaries were purchased from Thermo Fischer Scientific, (Waltham, MA, USA). The antibodies to pan-keratin, E-adhesion, and $\beta$-catenin were purchased from Cell Signaling Technology, Inc. (Danvers, MA, USA), VDR from Novus Biologicals (Littleton, CO, USA), and second antibody from Thermo Fischer Scientific, C57BL/6 female mice were obtained from the Experimental Animal Center (Soochow University, Suzhou, People's Republic of China). Care and treatment of mice were performed in strict accordance with the Guide for the Care and Use of Laboratory Animals of the National Science and Technology Committee. All protocols were approved by the Medical Research Ethics Committee of Jiangsu Province, People's Republic of China.

\section{Isolation and culture of ovarian epithelial cells}

Primary MOSE cells were isolated and modified as described by Roby et al. ${ }^{18}$ Briefly, ovaries from estrus female C57BL/6J mice were resected and rinsed with $100 \mathrm{mg} / \mathrm{mL}$ of penicillin and streptomycin three times. The ovaries were placed in $1.5 \mathrm{~mL}$ EP tube and incubated with the trypsin solution at $37^{\circ} \mathrm{C}$ in an incubator of $5 \% \mathrm{CO}_{2}$ for 15 minutes, and then put into another tube for second trypsinization. Single cells and clumps of MOSE were collected by mild centrifugation, and resuspended in a completed DMEM/F12 medium supplemented with 5\% fetal bovine serum, $1 \%$ penicillin-streptomycin, $10 \mathrm{ng} / \mathrm{mL}$ mouse Epithelial Growth Factor, 1\% insulin-transferrin-selenium, and $0.5 \mathrm{mg} / \mathrm{mL}$ hydrocortisone. Cells were routinely subcultured at $1: 3$ to $1: 6$ ratios, depending on their growth rates.

\section{Experimental animal model and histopathology}

Two-month-old female C57BL/6J mice were randomized into six groups of 12 animals each. The mice with surgically exposed ovaries were injected under the ovary bursa at a dose of $4 \mathrm{mg} / \mathrm{mL}$ of $0.05 \mathrm{~mL}$ DMBA (Sigma Chemical Co.). To investigate the effects of vitamin D on ovarian cancer directly implanted with DMBA, experiment design was conducted as shown in Figure 1 and the groups included: 1) a model, only treated by DMBA; 2) a 20-week vitamin D3 (VD) group (initiation + promotion), 


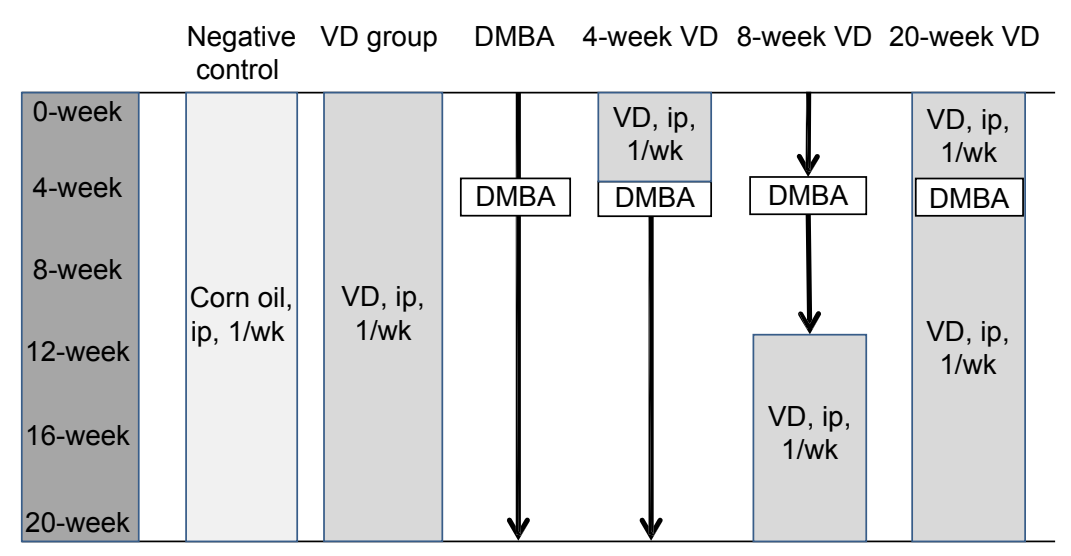

Figure I Experimental design used to evaluate the effects of vitamin D on DMBA-induced ovarian cancer in C57BL/6 mice.

Notes: I) Negative control group, corn oil was administered every week; 2) Vitamin D control group, vitamin D3 was administered ever week; 3 ) DMBA model, only treated by DMBA; 4) A 4-week VD group (initiation), vitamin D3 was administered every week from day 0 until a day prior to DMBA implanted; 5) An 8-week VD group (promotion), vitamin D3 was administered every week for 8 weeks following the DMBA implanted till the end of the study; and 6) A 20-week VD group (initiation + promotion), vitamin D3 was administered at a dose of $20,000 \mathrm{IU} / \mathrm{kg}$ every week for a duration of 20 weeks.

Abbreviations: DMBA, 7, I2-dimethylbenz [a] anthracene; ip, intraperitoneal; wk, week; VD, vitamin D3.

vitamin D3 was administered at a dose of 20,000 IU/kg every week for a duration of 20 weeks; 3) a 4-week VD group (initiation), vitamin D3 was treated every week from day 0 until the day prior to DMBA implanted; 4) a 8-week VD group (promotion), vitamin D3 was administered every week for 8 weeks till the end of the study after the DMBA implanted for 12 weeks; and 5) and 6) two additional negative control groups, corn oil and vitamin D3 were administered every week, respectively. Animals were weighed weekly and monitored for the development of ascites or palpable tumor formation for up to 90 days. At the time of sacrifice, organs were harvested and fixed in $10 \%$ buffered formalin. Routine paraffin embedding of tissues and hematoxylin and eosin staining of tissue sections were performed by the laboratory at Medical College of Soochow University (Suzhou, People's Republic of China).

\section{Soft agar assay}

Two thousand cells were mixed with $1 \mathrm{~mL}$ of $0.35 \%$ agarose and plated into $35 \mathrm{~mm}$ dishes with a bottom layer of $0.75 \%$ agarose. Cells were fed every 3 days with $1 \mathrm{~mL}$ culture medium. The colonies were counted 2 weeks after initial plating. Data are presented as ratios of the number of colonies to the number of plated cells. Data points in figures represent three independent experiments.

\section{Immunofluorescence}

Tumor samples were harvested from mice, trimmed into $\sim 5 \mathrm{~mm}^{3}$ pieces, and immediately coated with Cryo tissue-embedding compound (OCT, Leica Microsystems, Wetzlar, Germany). Frozen sections for immunofluorescence were selected, washed in phosphate-buffered saline, and fixed in $4 \%$ phosphate-buffered paraformaldehyde for 30 minutes. The goat blocking serum was applied for 10 minutes at room temperature. The sections were incubated with primary antibody at $4{ }^{\circ} \mathrm{C}$ overnight. After washing in phosphate-buffered saline, secondary antibody was applied for 10 minutes followed by $\mathrm{Cy} 5$ for E-cadherin and fluorescein isothiocyanate for $\beta$-catenin and VDR. The nuclei were stained with 4',6-diamidino-2-phenylindole. Fluorescence signals were detected using a confocal laser scanning microscope (Leica Microsystems). Ten visual fields were randomly selected and the fluorescent intensity of cells from a total of 500 cells stained with $\mathrm{Cy} 5$ or fluorescein isothiocyanate were quantified using the software Leica TCS SP2. The average fluorescent intensity was taken as the relative expression level.

\section{ELISA}

The level of CA125 (HCB, Vancouver, BC, Canada) and 25(OH)D (IBL International GmbH, Hamburg, Germany) in serum and ascites was detected by enzyme linked immunosorbent assay (ELISA) kit according to the manufacturer's instruction. Briefly, $100 \mu \mathrm{L}$ of each standard and samples were added into appropriate wells, and incubated for 2.5 hours at room temperature. After washing with wash buffer for four times, $100 \mu \mathrm{L}$ of prepared biotinylated antibody was applied to incubate for 1 hour at room temperature. After washing, $100 \mu \mathrm{L}$ of prepared streptavidin solution was incubated for 45 minutes. Ninety microliters of one-step substrate reagent was used to incubate for 30 minutes. The unwashed biotin-labeled CA125 or $25(\mathrm{OH}) \mathrm{D}$ that bound to the plate was detected by the addition of $50 \mu \mathrm{L}$ of stop solution which resulted in a colored product measured at 
$450 \mathrm{~nm}$ in a microplate reader (Molecular Devices Inc. San Francisco, CA, USA).

\section{Statistical analysis}

Statistical analysis was performed using SPSS, version 13.0 for Windows (SPSS Inc., Chicago, IL, USA). Data are presented as the mean \pm standard deviation. The comparison of distribution of variables between each group was made using the Student's $t$-test and variance analysis, with significance set at a $P$-value of less than 0.05 .

\section{Results}

\section{Characterization of MOSE cells}

As shown in Figure 2A, more than $90 \%$ of surface epithelia cells expressed a pan-keratin, an epithelial marker, which was identified as MOSE cells. The MOSE cells exhibited cobblestone morphology and contact inhibition of growth, which are typical characteristics of epithelial cells (Figure 2B). The early passage cells had a very slow growth rate. After cells were treated with DMBA, cobblestone morphology was no longer apparent and contact inhibition of growth was lost as evidenced by the growth of multiple layers of cells in 12th passage (Figure 2C). The malignant phenotype is defined by the ability to form colonies in soft agar in vitro (Figure 2D).

\section{Active vitamin $D$ delays malignant transformation of Mose cells induced by DMBA in vitro}

$1 \alpha, 25(\mathrm{OH})_{2} \mathrm{D}_{3}$ has been found to be a potential tumor preventive and therapeutic agent. ${ }^{12}$ We further tested whether
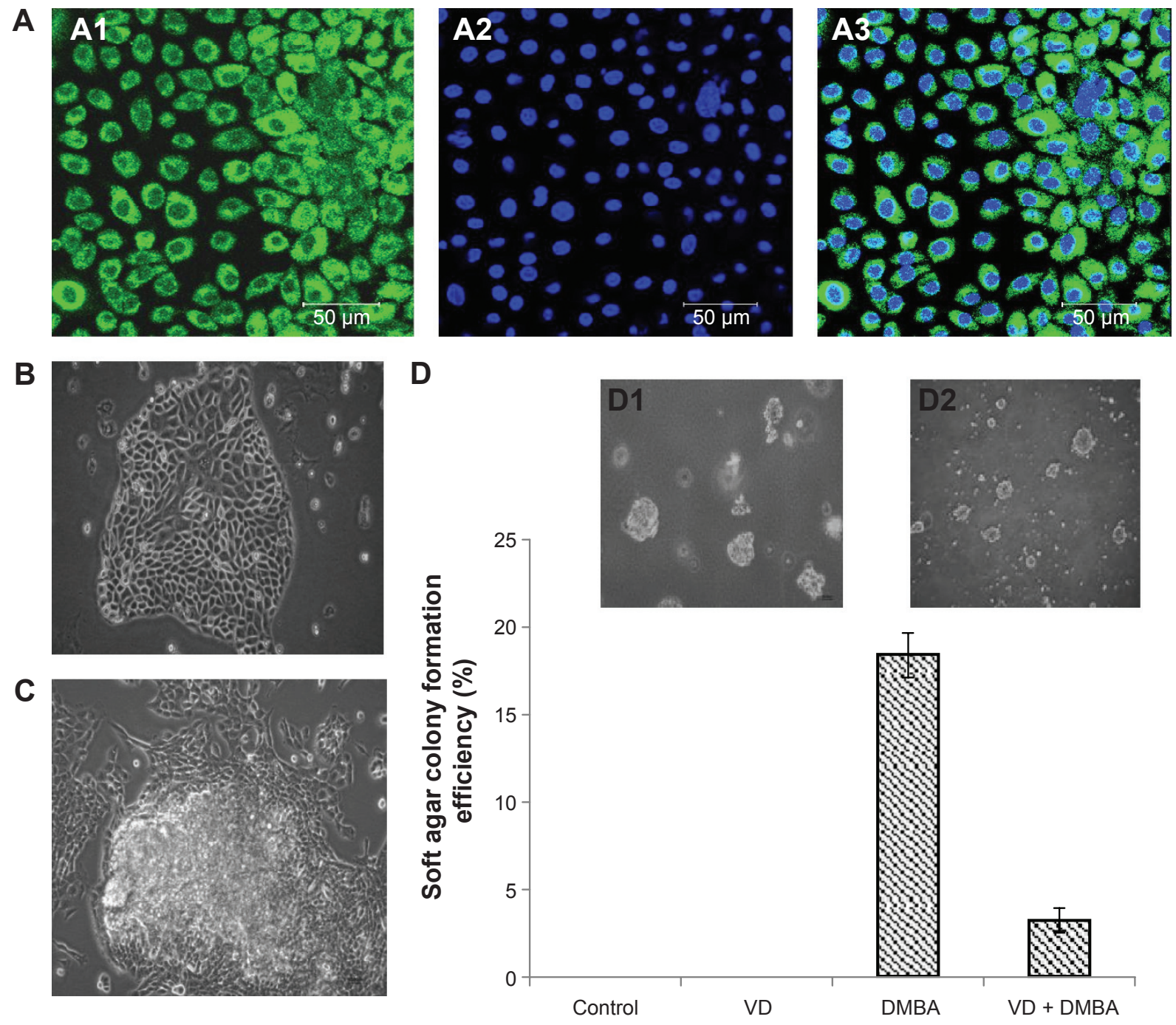

Figure 2 The effects of vitamin D on DMBA-induced malignant transformation of MOSE cells in vitro.

Notes: (A) MOSE cells expressed pan-keratin, an epithelial cell marker. Al: green pan-keratin; A2: blue nuclei; and A3: merge of Al and A2; (B) Early MOSE cells exhibited cobblestone morphology ( $\times 200)$; (C) Malignant transformation of MOSE cells showed the growth of multiple layers $(\times 200)$; $(\mathbf{D})$ I,25(OH) ${ }_{2} \mathrm{D}_{3}$ significantly decreased the colony formation rate of MOSE cells. DI, representative image of DMBA group $(\times 100)$. D2, representative image of 20-week VD group $(\times 100)$.

Abbreviations: DMBA, 7, I2-dimethylbenz [a] anthracene; MOSE, mouse ovarian surface epithelial; VD, vitamin D3. 
$1 \alpha, 25(\mathrm{OH})_{2} \mathrm{D}_{3}$ was able to inhibit malignant transformation of MOSE cells induced by DMBA. Compared with MOSE cells induced by DMBA only, MOSE cells administered together with $1 \alpha, 25(\mathrm{OH})_{2} \mathrm{D}_{3}$ appeared as the same malignant transformation in 15 th passage. The rate of colony formation was also significantly decreased from $18.4 \%$ to $3.2 \%$ $\left(P<0.05\right.$, Figure 2D). The results indicate that $1 \alpha, 25(\mathrm{OH})_{2} \mathrm{D}_{3}$ may delay malignant transformation of ovarian surface epithelial cells induced by DMBA.

\section{Establishment of ovarian cancer model of mouse-implanted DMBA}

We then tested whether vitamin D inhibited the development of ovarian cancer in vivo. For optimizing mouse model of ovarian cancer, DMBA was directly injected into the bursa of ovary in this study (Figure 3A). Twenty weeks posttreatment, no mice of negative control grew tumor, with an average ovary weight of $0.0126 \mathrm{~g}$. In contrast, $77.8 \%$ of mice implanted by DMBA showed signs of tumor growth, some with ascites. There were no tumors found in other places of mouse. The average weight of ovary including tumor was significantly increased to $0.301 \pm 0.0121 \mathrm{~g}$ (Table 1, $P<0.05)$. The CA125, a diagnostic indicator for ovarian cancer, was also aggressively increased to $4.75 \mathrm{U} / \mathrm{mL}$, compared to negative control $(0.75 \mathrm{U} / \mathrm{mL})$ (Table $1, P<0.05)$. Pathological examination in DMBA-induced group showed that the nucleus displayed obvious pleomorphism and the nuclear:cytoplasmic ratio was high. New vascularization was also found in tissue (Figure 3B). These results indicated that a mouse model of ovarian cancer was successfully established by directly implanting DMBA in the bursa of ovaries.

\section{Vitamin D suppresses ovarian tumor growth in vivo}

To test the role of vitamin $\mathrm{D}$ as a potential chemopreventive agent against the development of ovarian cancer, experimental design was used as shown in Figure 1. The incidence rate was reduced when DMBA-implanted mice were treated with vitamin D3 during initiation (55.6\%), promotion (50\%), and entire period (27.3\%), respectively (Table $1, P<0.05)$. The weight of ovary including tumor was also significantly decreased (Figure $3 \mathrm{C}, P<0.05$ ), and the general condition of the mice

\section{A}
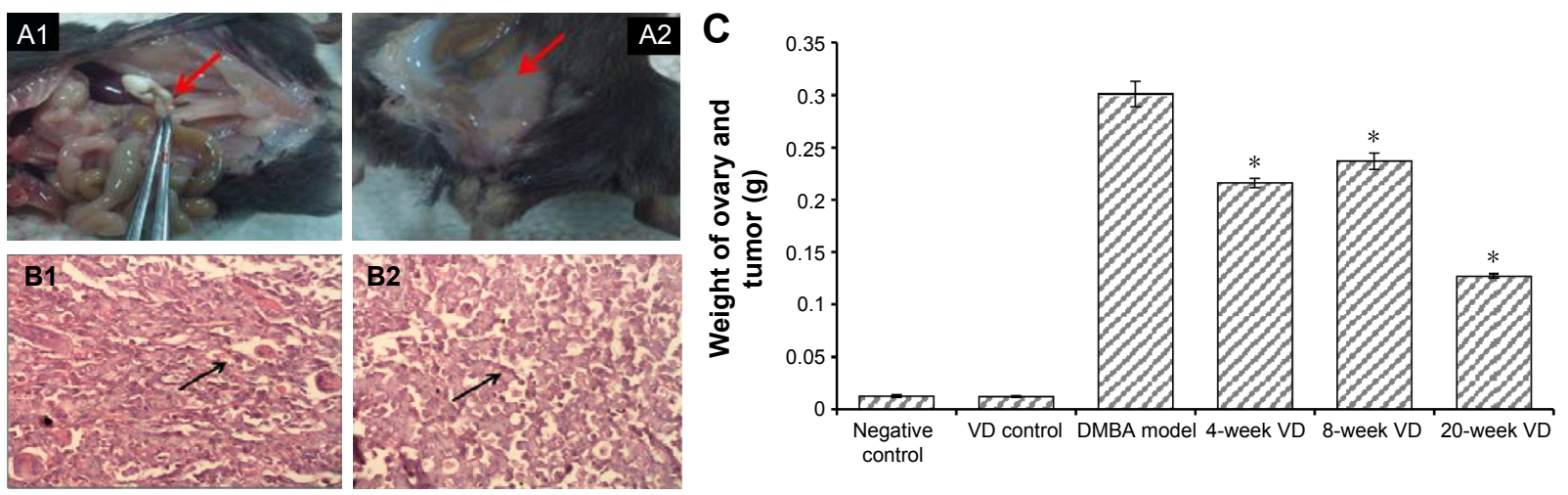

D
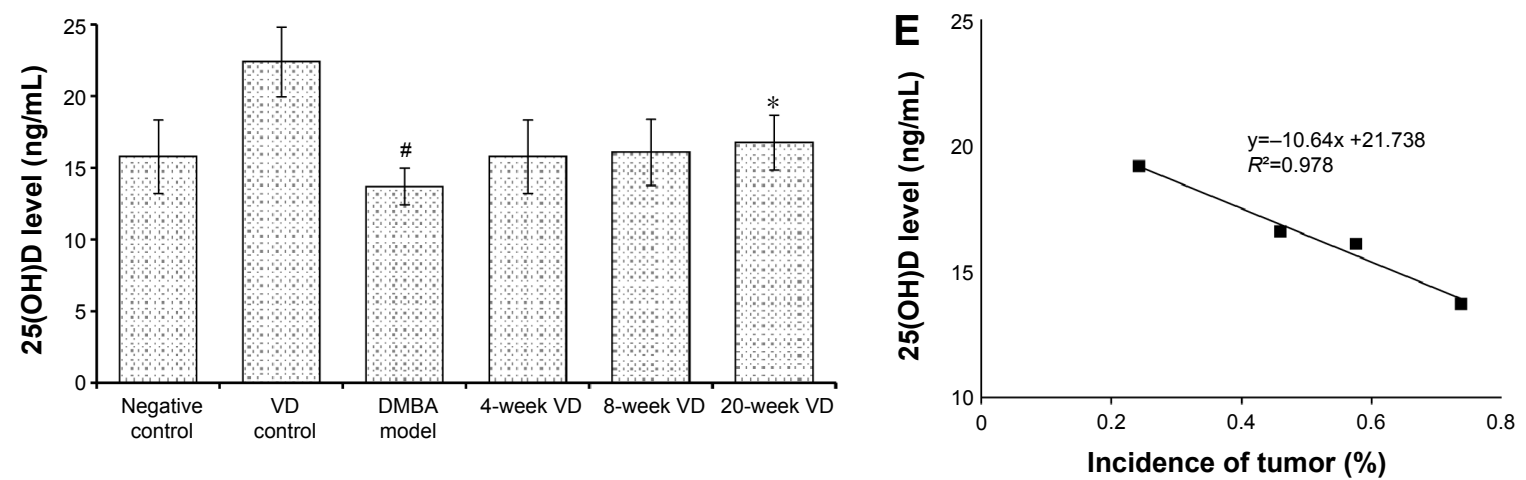

Figure 3 Vitamin D suppresses the growth of ovarian tumor directly implanted by DMBA in vivo.

Notes: (A) Representative picture of DMBA-induced neoplastic masses and ascites in abdominal cavity of mouse AI, neoplastic masses (red arrow) and A2, ascites (red arrow); (B) Histopathology of ovarian tumors induced by DMBA. B I, the nucleus displayed obvious pleomorphism (black arrow) and B2, new vascularization was also found in tissue (black arrow) (H\&E stain $\times 400$ ); (C) The weight of ovary including tumor was significantly decreased by vitamin $D$ treatment. Compared to $D M B A$ group, $* P<0.05$; (D) The $25(\mathrm{OH}) \mathrm{D}$ level of 20 -week VD group was the highest among all vitamin $\mathrm{D}$-treated groups. Compared to negative control group, ${ }^{\# P<0.05 ; ~ c o m p a r e d ~ t o ~ D M B A ~}$ model, $* P<0.05$; compared to DMBA group; $(E) A$ negative correlation between incidence of DMBA-induced tumor and $25(\mathrm{OH}) \mathrm{D}$ level in mice.

Abbreviations: DMBA, 7, I2-dimethylbenz [a] anthracene; H\&E, hematoxylin and eosin; VD, vitamin D3. 
Table I Vitamin D suppresses the growth of ovarian tumor implanted by DMBA in vivo

\begin{tabular}{|c|c|c|c|c|c|c|}
\hline \multirow[t]{2}{*}{ Group } & \multirow[t]{2}{*}{$\mathbf{N}$} & \multirow[t]{2}{*}{ Deaths } & \multirow[t]{2}{*}{ Incidence (\%) } & \multirow{2}{*}{$\begin{array}{l}\text { Weight of ovary } \\
\text { including tumor (g) }\end{array}$} & \multicolumn{2}{|c|}{ CAI $25(\mathrm{U} / \mathrm{mL})$} \\
\hline & & & & & Serum & Ascites \\
\hline Negative control & 12 & 0 & $0 / 24(0)$ & $0.0126 \pm 0.0014$ & $0.750 \pm 0.013$ & None \\
\hline VD control & 12 & 0 & $0 / 24(0)$ & $0.0121 \pm 0.0009$ & $0.915 \pm 0.021$ & None \\
\hline DMBA-induced model & 12 & 3 & 14/18 (77.8) & $0.30 \mathrm{I} \pm 0.012 \mathrm{I} *$ & $4.751 \pm 0.075^{*}$ & $5.87 \pm 0.091 *$ \\
\hline 4-week VD (initiation) & 12 & 3 & $10 / 18(55.6)$ & $0.216 \pm 0.0045^{*}$ & $3.326 \pm 0.063^{*}$ & $4.75 \pm 0.073$ \\
\hline 8-week VD (promotion) & 12 & 2 & $10 / 20(50.0)$ & $0.237 \pm 0.0076 *$ & $3.014 \pm 0.087^{*}$ & $4.26 \pm 0.069 *$ \\
\hline 20-week VD (initiation + promotion) & 12 & 1 & $6 / 22(27.3)$ & $0.127 \pm 0.0018^{*}$ & $2.160 \pm 0.045^{*}$ & $3.49 \pm 0.058$ \\
\hline
\end{tabular}

Note: *Compared with DMBA-induced model group, $P<0.05 . \mathrm{N}=$ number of mice. The incidence of ovarian cancer is ovaries with tumors/ovaries with DMBA. Abbreviations: DMBA, 7, I2-dimethylbenz [a] anthracene; VD, vitamin D3.

was improved, compared with DMBA-induced group. The CA125 level of both serum and ascites in vitamin D-treated groups, especially the 20 -week VD group (initiation + promotion), was significantly decreased compared with DMBAinduced groups (Table $1, P<0.05$ ).

We also tested the circulating $25(\mathrm{OH}) \mathrm{D}$ level in mice, a widely accepted biomarker of vitamin D status. Compared with negative control group, the $25(\mathrm{OH}) \mathrm{D}$ level of serum in DMBA model was significantly decreased, while that in VD control and 20-week VD group were significantly increased (Table S1). The $25(\mathrm{OH}) \mathrm{D}$ level in mice of 20-week VD group was the highest among all vitamin D-treated groups (Figure 3D, $P<0.05$ ). As showed in Figure 3E, there was a negative correlation between incidence of DMBA-induced tumor and 25(OH)D level $\left(R^{2}=0.978, P<0.05\right)$. These data collectively indicate that vitamin D3 plays a chemopreventive role in DMBA-induced ovarian cancer, and supplementation during the full phase (including initiation and promotion) is the most effective way.

\section{Vitamin D regulates expression of E-cadherin and $\beta$-catenin both in vitro and in vivo}

The morphological change from epithelial to mesenchymal was observed during the transformation of MOSE cells. So, we further assessed the expression of epithelial and mesenchymal markers in tumor tissue and MOSE cells by immunofluorescence staining (Figure 4). Contrary to negative controls, lower expression of VDR and E-cadherin, as well as higher expression of $\beta$-catenin, was found in DMBA model. However, the administration of vitamin D3 significantly increased the expression of VDR and E-cadherin (Figure $4 \mathrm{~A}$ and $\mathrm{B}$ ), and decreased the expression of $\beta$-catenin (Figure 4C). Similarly, we also found that $1 \alpha, 25(\mathrm{OH})_{2} \mathrm{D}_{3}$ increased the expression of E-cadherin, and decreased the expression of $\beta$-catenin in MOSE cells in vitro (Figure S1). These results show that vitamin $\mathrm{D}$ increases the expression of E-cadherin and decreases the expression of $\beta$-catenin, indicating vitamin D increased the expression of epithelial marker by increasing VDR level.

\section{Discussion}

Since ovarian cancer is the most lethal malignancy of the female reproductive system and the prevention and treatment of ovarian carcinoma are still far from optimal, animal models are still reasonably needed to be a helpful addition to understand the development and progression of ovarian carcinoma. In this study, we successfully established both in vitro and in vivo models for the development of epithelial ovarian cancer by DMBA. We also found that vitamin D not only delayed malignant transformation of ovarian surface epithelial cells induced by DMBA but also played a chemopreventive role in animal models directly implanted with DMBA. To our knowledge, this is the first report that the DMBA implantation in mice yields high incidence of ovarian cancer, specifically epithelial derived ovarian cancer.

The antineoplastic actions of $1 \alpha, 25(\mathrm{OH})_{2} \mathrm{D}_{3}$ and its analogs have been shown both in vitro and in vivo, in various malignancies, including ovarian cancer. For example, in EOC cells, $1 \alpha, 25(\mathrm{OH})_{2} \mathrm{D}_{3}$ caused cell cycle arrest at the $\mathrm{G} 2 / \mathrm{M}$ transition and $\mathrm{G} 1 / \mathrm{S}$ checkpoint, and decreased human telomerase reverse transcriptase mRNA stability through microRNA, the mechanism underlying $1 \alpha, 25(\mathrm{OH})_{2} \mathrm{D}_{3}$-induced cell death. ${ }^{19}$ Our previous study also demonstrated that $1 \alpha, 25(\mathrm{OH})_{2} \mathrm{D}_{3}$ suppressed SKOV-3 cell growth, and enhanced the antiproliferative effect of carboplatin by increasing apoptosis and reactive oxygen species production and reducing mitochondrial membrane potential. ${ }^{6}$ In the present study, $1 \alpha, 25(\mathrm{OH})_{2} \mathrm{D}_{3}$ postponed malignant transformation of MOSE cells by increasing E-cadherin and decreasing $\beta$-catenin expression. Thus, these results give strong evidence supporting the use of $1 \alpha, 25(\mathrm{OH})_{2} \mathrm{D}_{3}$ as an antiproliferation agent for ovarian cancer cells in vitro.

The chemopreventive actions of vitamin $\mathrm{D}$ have been conducted in experimental lung, mammary and colon carcinogenesis, and neuroblastoma. ${ }^{20,21}$ These studies supported 

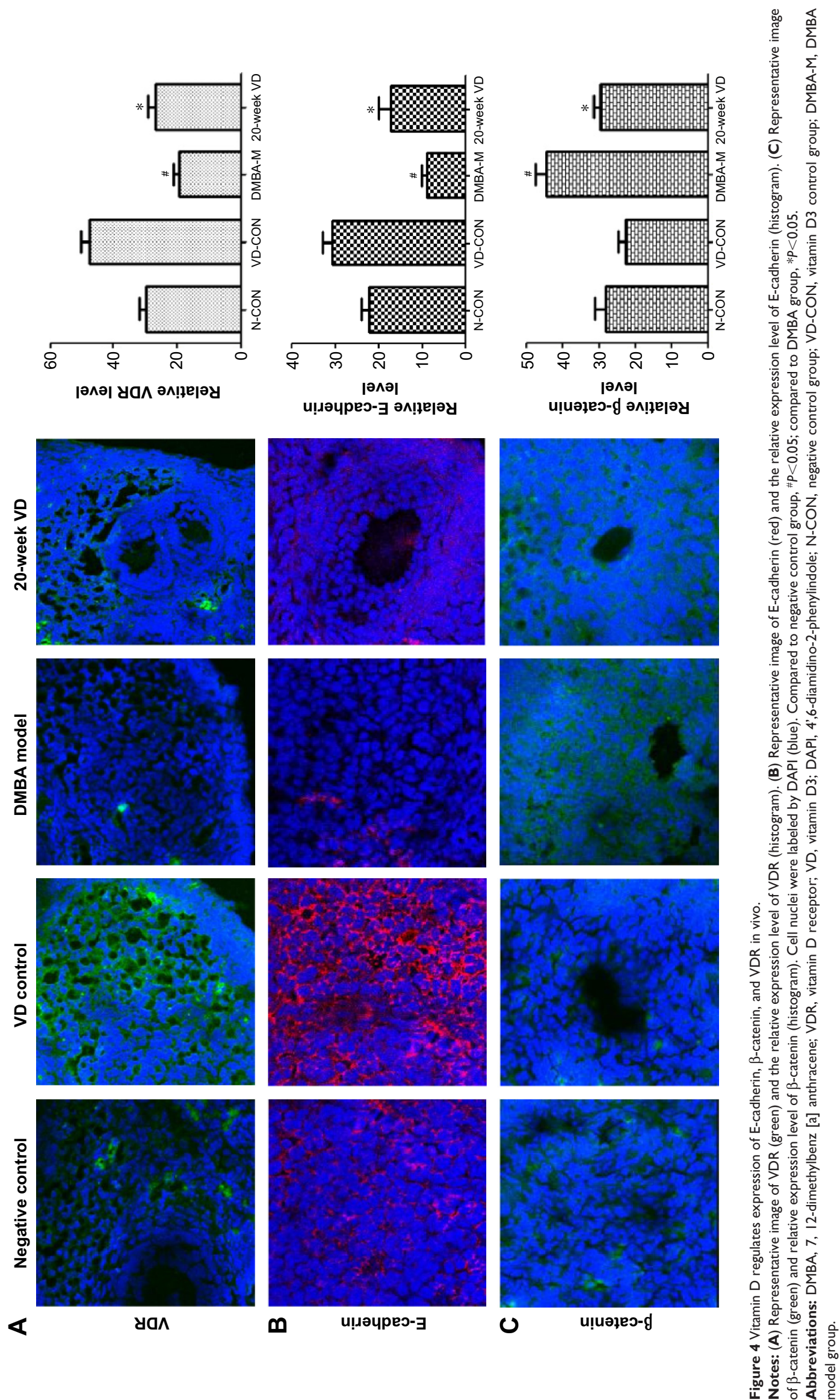

m

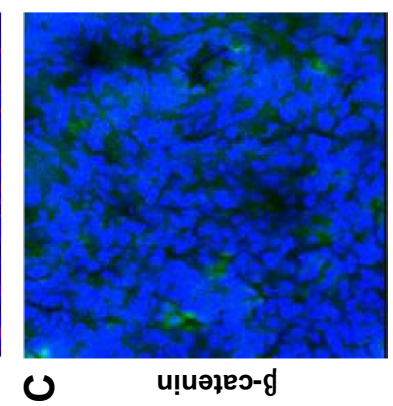

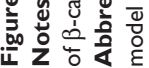


that vitamin D or its analogs suppressed development of chemical-induced tumor. In the present study, vitamin D3 was administrated during initiation, promotion, and the full phase of ovarian tumor, respectively. Our results show that the efficacy of vitamin D on inhibiting tumor growth has been demonstrated to be dependent on the timing of administration, and supplementation during the full phase (including initiation and promotion) is the most effective way. Moreover, vitamin D3 also reduced the content of CA125 in both serum and ascites, especially in the 20-week vitamin D3 group. Furthermore, the incidence of ovarian cancer was negatively correlated with the level of $25(\mathrm{OH}) \mathrm{D}$ in mice. In addition, the level of serum calcium was not obviously changed among groups (Table S2), which indicated that a high dose of vitamin $\mathrm{D}$ (with a dose of 20,000 IU/kg per week for duration of 20 weeks) did not trigger side effects of elevated serum calcium. These results indicate that vitamin D may delay the progression of ovarian tumors, and it is more effective to supplement with vitamin D at the entire stage than only at initiation or promotion of tumor development. Therefore, the results from in vivo antitumor activity suggest that vitamin $\mathrm{D}$ is a promising agent for cancer intervention.

The biological actions of vitamin $\mathrm{D}$ are mediated by VDR, mostly via genomic actions. The lower level of $25(\mathrm{OH}) \mathrm{D}$ and VDR is tightly associated with ovarian cancer. ${ }^{19,22-24}$ It is reported $^{25}$ that $1 \alpha, 25(\mathrm{OH})_{2} \mathrm{D}_{3}$ targeted the wnt $/ \beta$-catenin pathway by upregulating E-cadherin, but this is only possible when VDR presents. It is well known that E-cadherin is a key protein existing in normal epithelial cells and is involved in the adhesion properties. ${ }^{25}$ The downregulation of E-cadherin is regarded to be closely associated with the invasive metastasis, and poor prognoses of tumor. ${ }^{26}$ Our study not only figured lower expression of E-cadherin in ovarian tumor compared to the negative control and vitamin D-treated group but also confirmed that $1 \alpha, 25(\mathrm{OH})_{2} \mathrm{D}_{3}$ suppresses the development of ovarian tumor by upregulating the expression of VDR and E-cadherin and decreasing the expression of $\beta$-catenin. These data suggest that downregulation of E-cadherin might play a role in the development of ovarian tumor, and vitamin D treatment strategies can be targeted to increase E-cadherin and VDR expression to play a protective role in ovarian tumor progression.

One potential limitation of current study is the poor understanding of the etiology of spontaneous epithelial ovarian cancer. The development of chemical-induced model might be hampered by the presence of carcinogen, as many other specific promoters for the ovaries might be missed. A mechanistic understanding of ovarian cancer initiation, progression, and early stages of metastasis is hindered by the complexity of genetic and/or environmental initiating events and lack of clarity regarding the cell(s) or tissue(s) of origin. It is still important that investigators seek to develop a model that would effectively represent spontaneous human epithelial ovarian cancer.

\section{Conclusion}

In conclusion, vitamin D not only delayed malignant transformation of ovarian surface epithelial cells induced by DMBA but also played a chemopreventive role in animal models directly implanted with DMBA. Vitamin D delays the development progress of ovarian cancer by upregulating E-cadherin and VDR and downregulating $\beta$-catenin. However, spontaneous EOC models are still to be explored for testing preventive or therapeutic agents for epithelial ovarian cancer.

\section{Acknowledgments}

This study was supported by the National Natural Scientific Funding of China (grant nos 81072286 and 81372979) and in part by the Collaborative Innovation Center of Radiation Medicine, Jiangsu Higher Education Institutions.

\section{Disclosure}

The authors report no conflicts of interest in this work.

\section{References}

1. GLIBOCAN 2012: Estimated Cancer Incidence, Mortality and Prevalence Worldwide in 2012. 2012; version 1.2. Available from: http://globocan.iarc. fr/Pages/fact_sheets_population.aspx. Accessed December 12, 2013.

2. Jelovac D, Armstrong DK. Recent Progress in the Diagnosis and Treatment of Ovarian Cancer. CA Cancer J Clin. 2011;61(3):183-203.

3. Murthy S, Agoulnik IU, Weigel NL. Androgen receptor signaling and vitamin D receptor action in prostate cancer cells. Prostate. 2005; 64(4):362-372.

4. Peterlik M, Grant WB, Cross HS. Calcium, vitamin D and cancer. Anticancer Res. 2009;29(9):3687-3698.

5. Krishnan AV, Swami S, Feldman D. Equivalent anticancer activities of dietary vitamin D and calcitriol in an animal model of breast cancer: importance of mammary CYP27B1 for treatment and prevention. J Steroid Biochem Mol Biol. 2013;136:289-295.

6. Zhang Z, Zhang H, Hu Z, Wang P, Wan J, Li B. Synergy of 1,25dihydroxyvitamin D3 and carboplatin in growth suppression of SKOV-3 cells. Oncol Lett. 2014;8(3):1348-1354.

7. Yin L, Grandi N, Raum E, Haug U, Arndt V, Brenner H. Meta-analysis: Circulating vitamin D and ovarian cancer risk. Gynecol Oncol. 2011; 121(2):369-375.

8. Brock KE, Huang WY, Fraser DR, et al. Diabetes prevalence is associated with serum 25-hydroxyvitamin D and 1,25-dihydroxyvitamin D in US middle-aged Caucasian men and women: a cross-sectional analysis within the Prostate, Lung, Colorectal and Ovarian Cancer Screening Trial. Br J Nutr. 2011;106(3):339-344.

9. Toriola AT, Surcel HM, Calypse A, et al. Independent and joint effects of serum 25-hydroxyvitamin D and calcium on ovarian cancer risk: a prospective nested case-control study. Eur J Cancer. 2010;46(15): $2799-2805$. 
10. Toriola AT, Surcel HM, Agborsangaya C, et al. Serum 25-hydroxyvitamin D and the risk of ovarian cancer. Eur J Cancer. 2010;46(2):364-369.

11. Grant WB. Good evidence exists that solar ultraviolet-B and vitamin D reduce the risk of ovarian cancer. Am J Obstet Gynecol. 2010; 203(5):e10; author reply e10-e11.

12. Webb PM, de Fazio A, Protani MM, et al. Circulating 25-hydroxyvitamin $\mathrm{D}$ and survival in women with ovarian cancer. Am J Clin Nutr. 2015; 102(1):109-114.

13. Feldman D, Krishnan AV, Swami S, Giovannucci E, Feldman BJ. The role of vitamin D in reducing cancer risk and progression. Nat Rev Cancer. 2014;14(5):342-357.

14. Huang Y, Jiang W, Wang Y, Zheng Y, Cong Q, Xu C. Enhanced efficacy and specificity of epithelial ovarian carcinogenesis by embedding a DMBA-coated cloth strip in the ovary of rat. J Ovarian Res. 2012;5:21.

15. Marion SL, Watson J, Sen N, Brewer MA, Barton JK, Hoyer PB 7,12-dimethylbenz[a]anthracene-induced malignancies in a mouse model of menopause. Comp Med. 2013;63(1):6-12.

16. Chuffa LGA, Fioruci-Fontanelli BA, Mendes LO, et al. Characterization of chemically induced ovarian carcinomas in an ethanol-preferring rat model: Influence of long-term melatonin treatment. PloS one. 2013;8(12).

17. Miyata M, Furukawa M, Takahashi K, Gonzalez FJ, Yamazoe Y. Mechanism of 7,12-dimethylbenz[a]anthracene-induced immunotoxicity: role of metabolic activation at the target organ. Jpn J Pharmacol. 2001;86(3): 302-309.

18. Roby KF, Taylor CC, Sweetwood JP, et al. Development of a syngeneic mouse model for events related to ovarian cancer. Carcinogenesis. 2000;21(4):585-591.
19. Lungchukiet P, Sun Y, Kasiappan R, et al. Suppression of epithelial ovarian cancer invasion into the omentum by 1alpha,25-dihydroxyvitamin D3 and its receptor. J Steroid Biochem Mol Biol. 2015;148:138-147.

20. Mazzilli SA, Hershberger PA, Reid ME, et al. Vitamin D repletion reduces the progression of premalignant squamous lesions in the NTCU lung squamous cell carcinoma mouse model. Cancer Prev Res (Phila). 2015;8(10):895-904.

21. Lange TS, Zou Y, Singh RK, et al. Chemotherapeutic effect of calcidiol derivative B3CD in a neuroblastoma xenograft model. Chem Biol Drug Des. 2010;76(2):164-173.

22. Grant DJ, Hoyo C, Akushevich L, et al. Vitamin D receptor (VDR) polymorphisms and risk of ovarian cancer in Caucasian and African American women. Gynecol Oncol. 2013;129(1):173-178.

23. Mostowska A, Sajdak S, Pawlik P, Lianeri M, Jagodzinski PP. Vitamin D receptor gene BsmI and FokI polymorphisms in relation to ovarian cancer risk in the polish population. Genet Test Mol Biomarkers. 2013;17(3):183-187.

24. Deeb KK, Trump DL, Johnson CS. Vitamin D signalling pathways in cancer: potential for anticancer therapeutics. Nat Rev Cancer. 2007;7(9):684-700

25. Stubbins RE, Hakeem A, Nunez NP. Using components of the vitamin D pathway to prevent and treat colon cancer. Nutr Rev. 2012;70(12): 721-729.

26. Hugh TJ, Dillon SA, Taylor BA, Pignatelli M, Poston GJ, Kinsella AR. Cadherin-catenin expression in primary colorectal cancer: a survival analysis. Br J Cancer. 1999;80(7):1046-1051. 


\section{Supplementary materials}
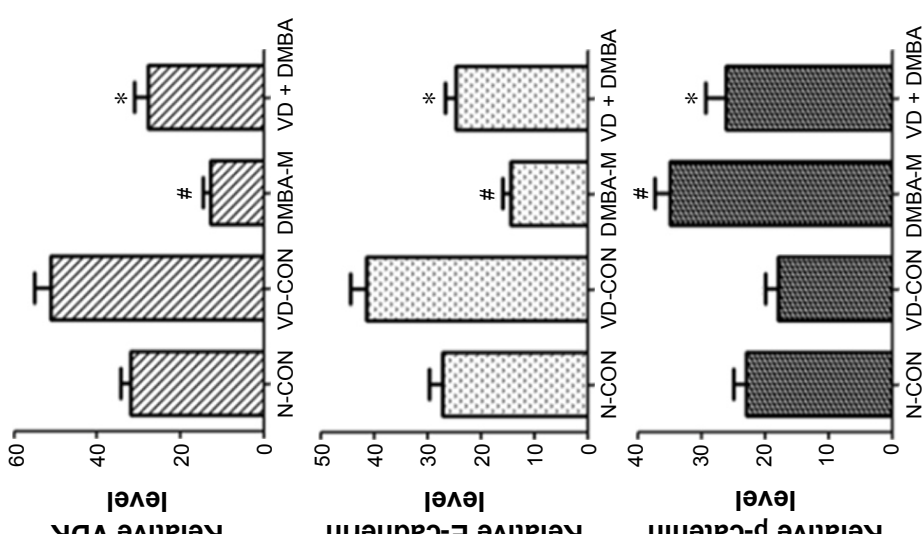

уа^ әм!џе|әу

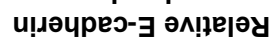

u!uәฺео-g әм!ฺе|әу
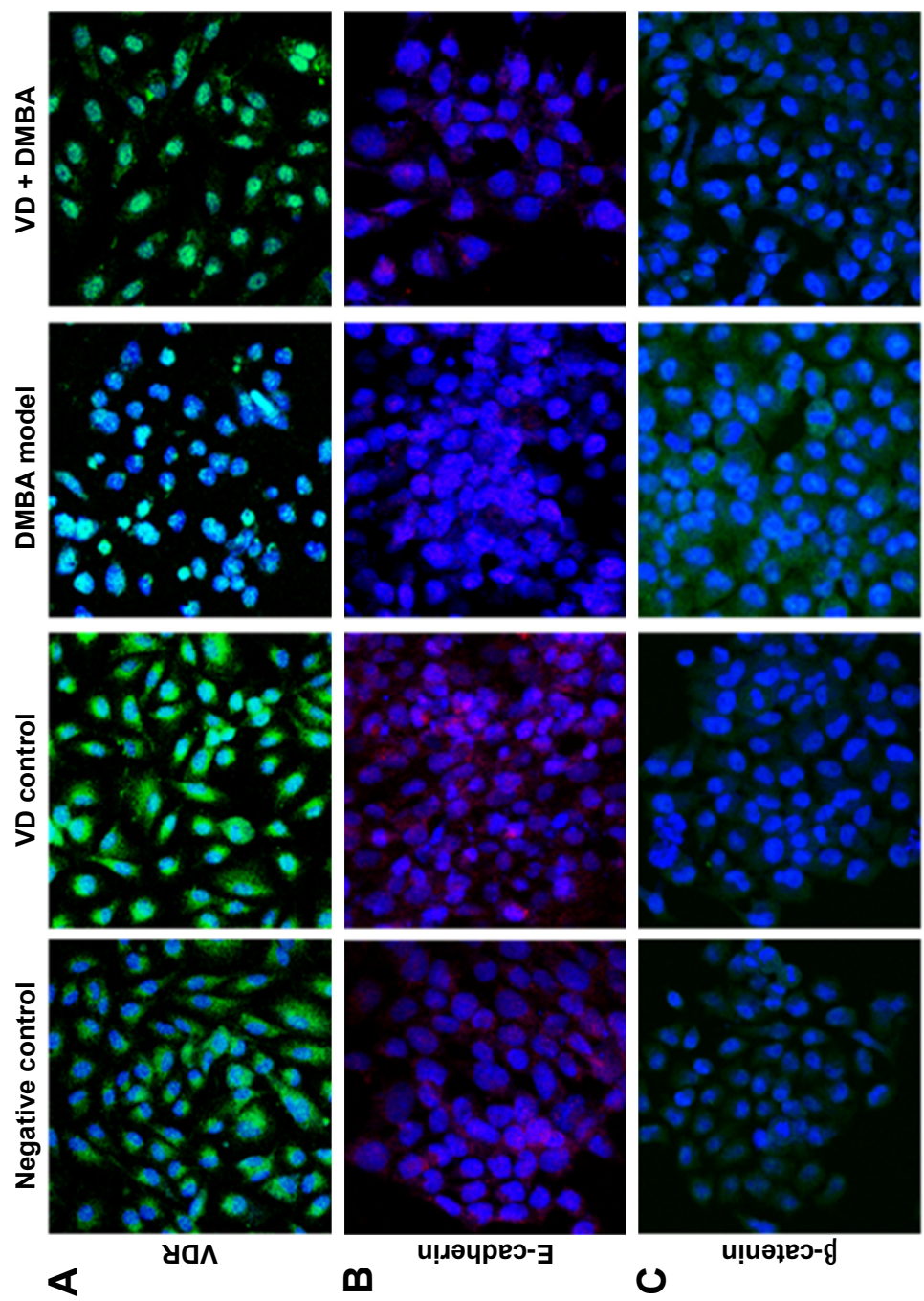

ต
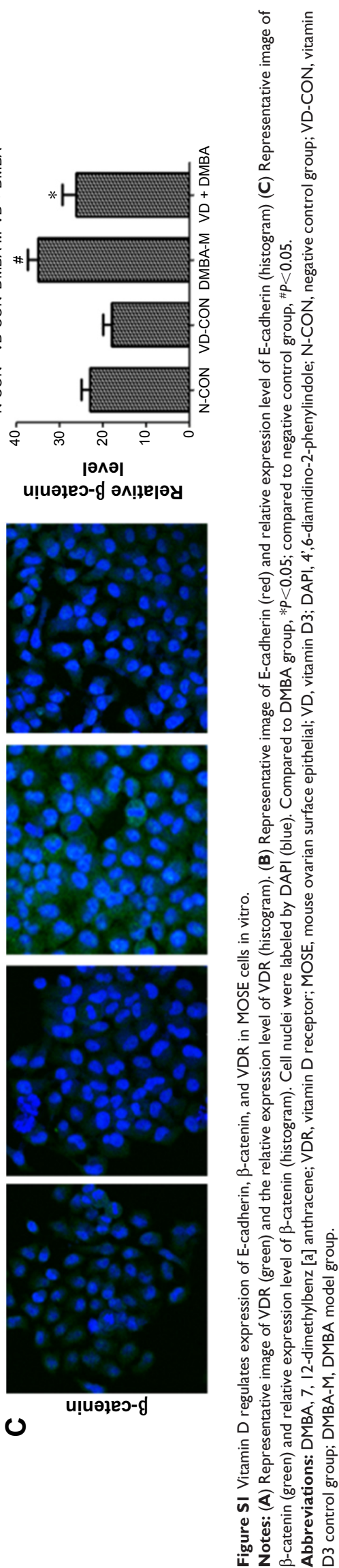
Table SI The 25(OH)D level in serum of mice

\begin{tabular}{lll}
\hline Group & Mean (ng/mL) & $\begin{array}{l}\text { Standard } \\
\text { deviation }\end{array}$ \\
\hline Negative control & 15.769 & 2.564 \\
VD control & $22.385^{\#}$ & 2.429 \\
DMBA model & $13.692^{*}$ & 1.289 \\
4-week VD (initiation) & 15.769 & 2.564 \\
8-week VD (promotion) & 16.076 & 2.311 \\
20-week VD (initiation + promotion) & $16.769^{\#, \Delta}$ & 1.918 \\
\hline
\end{tabular}

Notes: Compared with negative control group, the $25(\mathrm{OH}) \mathrm{D}$ level of serum in DMBA model was significantly decreased $(* P<0.05)$, while that in VD control and 20 -week VD significantly increased $(\# P<0.05)$. Compared with DMBA model, the $25(\mathrm{OH}) \mathrm{D}$ level in 20-week VD was dramatically increased $\left({ }^{\triangle} P<0.0 \mathrm{I}\right)$.

Abbreviations: DMBA, 7, 12-dimethylbenz [a] anthracene; VD, vitamin D3.

Table S2 The concentration of serum calcium in mice

\begin{tabular}{ll}
\hline Group & Calcium (mmol/L) \\
\hline Negative control & $2.73 \pm 0.317$ \\
VD control & $2.95 \pm 0.289$ \\
DMBA-induced model & $2.57 \pm 0.265$ \\
4-week VD (initiation) & $2.79 \pm 0.183$ \\
8-week VD (promotion) & $2.83 \pm 0.324$ \\
20-week VD (initiation + promotion) & $2.98 \pm 0.207$ \\
\hline
\end{tabular}

Abbreviations: DMBA, 7, I2-dimethylbenz [a] anthracene; VD, vitamin D3.

\section{Publish your work in this journal}

OncoTargets and Therapy is an international, peer-reviewed, open access journal focusing on the pathological basis of all cancers, potential targets for therapy and treatment protocols employed to improve the management of cancer patients. The journal also focuses on the impact of management programs and new therapeutic agents and protocols on
Dovepress

patient perspectives such as quality of life, adherence and satisfaction. The manuscript management system is completely online and includes a very quick and fair peer-review system, which is all easy to use. Visit http://www.dovepress.com/testimonials.php to read real quotes from published authors.

\footnotetext{
Submit your manuscript here: http://www.dovepress.com/oncotargets-and-therapy-journal
} 